\title{
Editorial on the occasion of the 70th birthday of Prof. Dr. Ing. Friedrich Jung
}

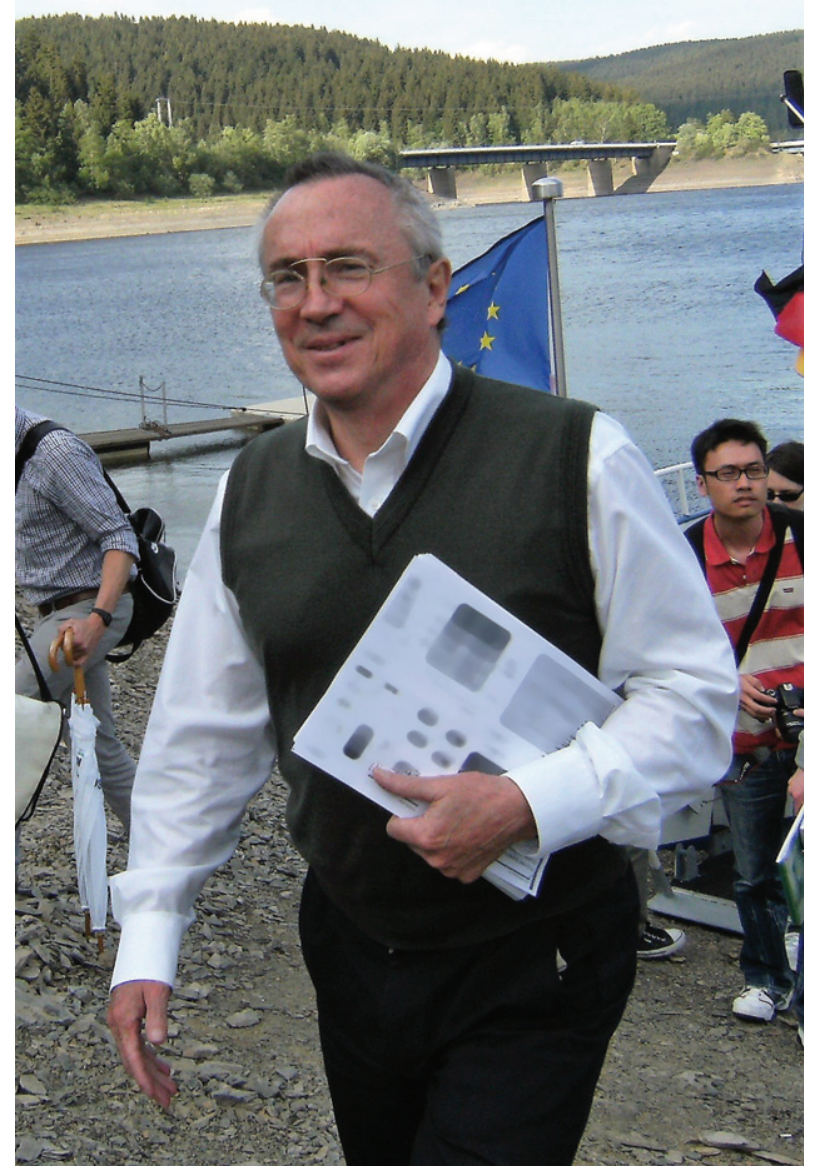

It is a great privilege for us - on the occasion of the 70th birthday of Prof. Dr. Ing. Friedrich Jung to honor his inspiring work for the scientific world, particularly in the field of Clinical Hemorheology and Microcirculation and the field of Biomaterials for Medical Applications.

Friedrich Jung was born on the 9th of November in the year 1947 in Grevenbroich (formerly known as Gindorf), North-Rhine Westphalia, Germany as son of the salesman Gerhard Friedrich Jung and his wife Josefine Jung and as beloved brother of Hans Wilbert Jung. Freed from the constraints of his unloved school life, he dedicated himself deeply to science.

Friedrich Jung started his student life in Aachen, initially being interested in Nuclear Techniques (1971). At the Technical University in West Berlin he then focused on Physical Engineering Science, with special emphasis on Thermodynamics and Fluid Dynamics. After his graduation, he decided to stay in Berlin and (1977) to deepen his knowledge in this field. 
Seeking to overcome the restrictions of the 'dry' physical sciences, he decided to pave the alley for new challenges at the Rheinisch-Westfälische Technische Hochschule Aachen (RWTH-Aachen) and went to the Department of Physiology to work in the "Red Cell Lab" of Prof. Holger Schmid-Schönbein. There, he defended his doctoral dissertation in 1985 in Physical Engineering and successfully intensified his haemorheological studies.

Deeply interested in clinical physiology and equipped with the knowledge and skills of an engineer, he moved to the University of Saarland in 1989 and started working in the department of Clinical Haemostasiology and Transfusion Medicine, where he was awarded with his habilitation in Biomedical Engineering in 1992.

Four years later, he became director of the Institute for Cardiovascular Research (Institut für Herzund Kreislaufforschung) in Dresden before - in 2007 - he expanded his scientific portfolio ones more to the research on cardiovascular implant materials in the Institute of Biomaterial Science of the Helmholtz-Zentrum Geesthacht (HZG, formerly: GKSS, Institute of Polymer Research, Center for Biomaterial Development) in Teltow and the Berlin Brandenburg Centre for Regenerative Therapies (BCRT). Until today, he is leading the department of Biointerface Engineering and is inspiring the people around him.

His scientific achievements comprise more than 570 peer reviewed publications, 215 book chapters and 10 books (we tried to collect all data on this, however, the true numbers seem to increase monthly). His bustling publishing work includes the chief-editorship for the Clinical Hemorheology and Microcirculation (since 2001), for the Journal of Applied Cardiopulmonary Pathophysiology (since 2009) and for the Journal of Cellular Biotechnology (since 2014). Friedrich Jung held the vice-presidency and presidency of the European Society for Clinical Hemorheology and Microcirculation (2002-2008) and was repeatedly honored during his career; inter alia with the Oskar Orth award (1990, Saarland University), the Otfried-Müller award (1996, German Socienty for Clinical Hemorheology and Microcirculation), the honorary medal of the Bayerische Röntgengesellschaft (2008, for special scientific achievements) and the Robin Fåhraeus Medal (2009, European Society for Clinical Hemorheology and Microcirculation).

Beyond these scientific achievements, which can be easily put in numbers, stands a man also with highest human values. Being, a real gentleman with an encyclopedic knowledge and with an exceptional memory, he is always to the point and with an ironic sense of humor widely respected among scientists. During his entire working life, he profoundly inspired and motivated students and colleagues with his broad fundamental knowledge, his ability to connect researchers from different fields to overcome the (often intrinsic) scientific boundaries and, none the less, with the patience of a saint. We would like to thank an outstanding scientist and friend. Dear Friedel, thank you for everything!!! Moreover, this thank is also dedicated to his family-Margrit and Conrad-, who have strengthened and kept his back in all of these years, so that he was able to dedicate himself to his greatest passion without hindrance, the science.

We wish you a long, healthy and happy life and hope to work with you together for a further decade of fruitful scientific work.

We would like to end with the following words:

Wie schön dass du geboren bist, wir hätten dich sonst sehr vermisst! (How beautiful that you were born, otherwise we would have missed you a lot!, Rolf Zuckowski)

Anne Krüger-Genge and Steffen Braune

Institute of Biomaterial Science and Berlin-Brandenburg Centre for Regenerative Therapies (BCRT), Helmholtz-Zentrum Geesthacht, Kantstrasse 55, 14513 Teltow, Germany 